\title{
Treating Rare Diseases in Africa: The Drugs Exist but the Need Is Unmet
}

\author{
Lucio Luzzatto $^{1,2 *}$ and Julie Makani ${ }^{1}$ \\ ${ }^{1}$ Department of Haematology and Blood Transfusion, Muhimbili University of Health and Allied Sciences, Dar-es-Salaam, \\ Tanzania, ${ }^{2}$ University of Florence, Florence, Italy
}

\section{OPEN ACCESS}

Edited by:

Timothy Martin Cox, University of Cambridge,

United Kingdom

Reviewed by:

Michael Laffan,

Imperial College London,

United Kingdom

Derralynn Hughes,

University College London,

United Kingdom

*Correspondence:

Lucio Luzzatto

Iluzzatto@blood.ac.tz

Specialty section:

This article was submitted to

Drugs Outcomes Research and

Policies,

a section of the journal

Frontiers in Pharmacology

Received: 04 September 2021

Accepted: 08 December 2021

Published: 10 January 2022

Citation:

Luzzatto L and Makani J (2022) Treating Rare Diseases in Africa: The

Drugs Exist but the Need is Unmet.

Front. Pharmacol. 12:770640.

doi: 10.3389/fphar.2021.770640
Rare diseases $(\mathrm{RD})$ pose serious challenges in terms of both diagnosis and treatment. Legislation was passed in the US (1983) and in EU (2000) aimed to reverse the previous neglect of RD, by providing incentives for development of "orphan drugs" (OD) for their management. Here we analyse the current situation in Africa with respect to (1) sickle cell disease (SCD), that qualifies as rare in the US and in EU, but is not at all rare in African countries (frequencies up to 1-2\%); (2) paroxysmal nocturnal haemoglobinuria (PNH), that is ultra-rare in Africa as everywhere else (estimated $<10$ per million). SCD can be cured by bone marrow transplantation and recently by gene therapy, but very few African patients have access to these expensive procedures; on the other hand, the disease-ameliorating agent hydroxyurea is not expensive, but still the majority of patients in Africa are not receiving it. For $\mathrm{PNH}$, currently most patients In high income countries are treated with a highly effective OD that costs about $\$ 400,000$ per year per patient: this is not available in Africa. Thus, the impact of OD legislation has been practically nil in this continent. As members of the medical profession and of the human family, we must aim to remove barriers that are essentially financial: especially since countries with rich economies share a history of having exploited African countries. We call on the Global Fund to supply hydroxyurea for all SCD patients; and we call on companies who produce ODs to donate, for every patient who receives an expensive OD in a high income country, enough of the same drug, at a symbolic price, to treat one patient in Africa.

Keywords: sickle cell disease, paroxysmal nocturnal haemoglobinuria, hydroxyurea, eculizumab, orphan drugs, public health versus profit, cost of production-price mismatch, post-colonial debt

\section{INTRODUCTION}

The challenges posed by Rare Diseases have evolved in recent times in at least three ways. 1) Improved diagnosis. When the older between us was a medical student, identifying a patient with, for instance, Fanconi anaemia or Fabry disease, was regarded as an achievement of clinical acumen supported by specialized laboratory methodology: the diagnosis was often made by the individual effort of an obsessed clinical investigator. Now, in many cases, a clinical suspicion triggers DNA testing of an appropriate gene panel that can quickly confirm or refute the suspicion. 2) Increased awareness and patient empowerment. There is now a vast number of formally constituted or informal Patient Groups: a healthy development in our view. ORPHANET (https://www.orpha.net/consor/cgi-bin/index.php?lng=EN), founded in France, is now a global organization, particularly active in $\mathrm{EU}$, that lists over 7,000 rare diseases and provides a wealth of information and activities; NORD (https://rarediseases.org) has a similar role in the US. 3) Legislation in the US and in Europe has introduced "Orphan Drug Designation" by FDA 


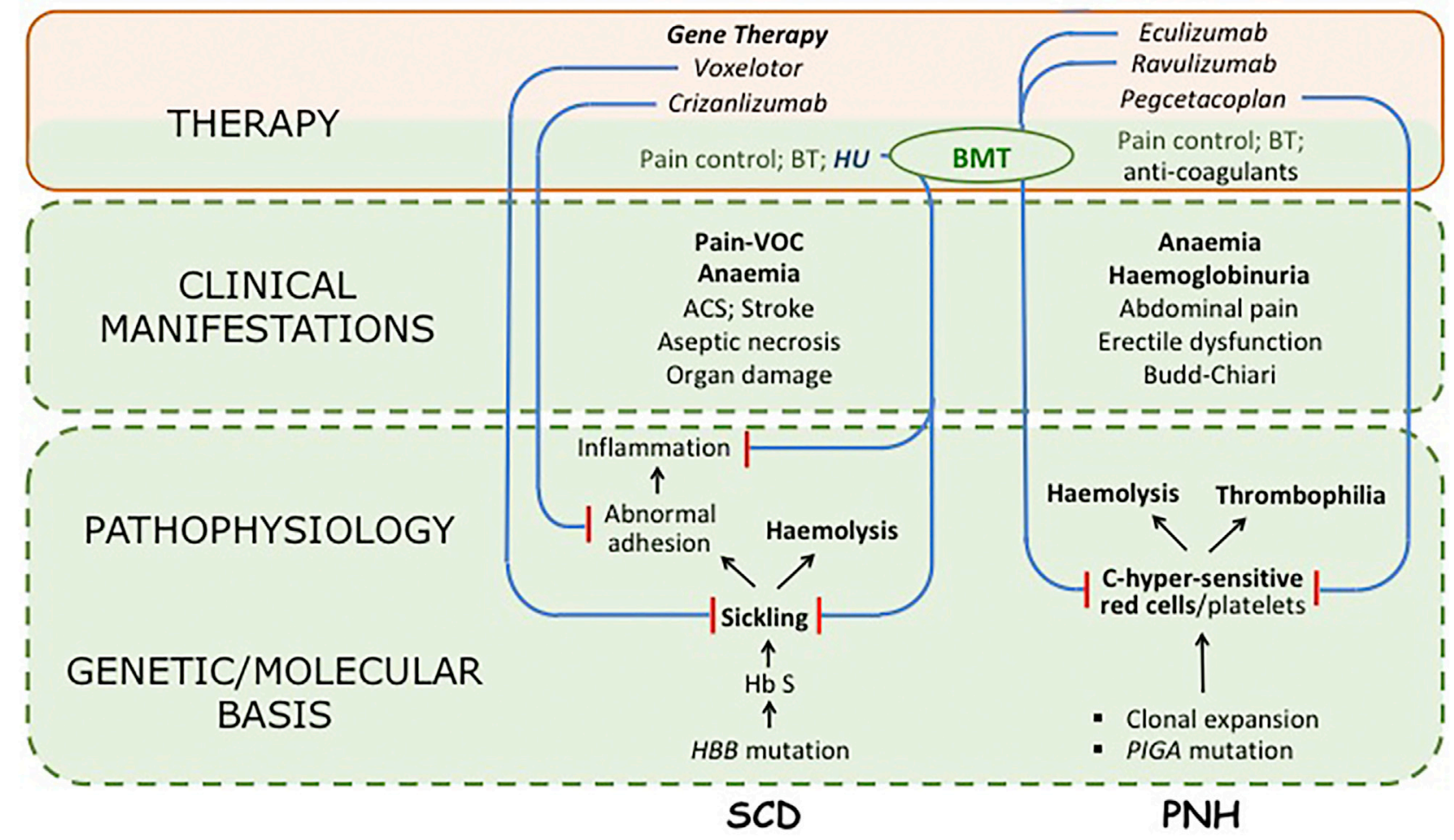

FIGURE 1 | Synoptic view of two Rare Diseases, sickle cell disease (SCD) and paroxysmal nocturnal haemoglobinuria (PNH), and of drugs used in their treatment. For both diseases the pathophysiology is complex; but in SCD the primary problem is clearly sickling, whereas other features are important consequences, particularly a chronic inflammatory state; in PNH the primary abnormality is in the deficiency of the GPI-linked surface proteins CD55 and CD59, that make both red cells and platelets exquisitely sensitive to activated complement (C) (although it is not yet certain whether the marked thrombophilic tendency is a direct consequence of the platelet abnormality or an indirect consequence of intravascular haemolysis). For both diseases only major clinical manifestations are listed (VOC stands for vaso-occlusive crisis). Regarding therapy, long-established supportive measures are in green type; drugs are in italic; curative treatments are in bold: all other treatments are disease-modifying. Blue lines ending in red bars indicate the mechanism of action of targeted drugs; in PNH each drug inhibits in one way or another activation of complement (eculizumab and ravulizumab bind to C5; pegcetacoplan binds to C3: for details see (Luzzatto, 2021)). BT stands for blood transfusion; BMT indicates bone marrow transplantation (used successfully in both SCD and PNH). The area shaded in light green reflects the body of work that has led to identification of the molecular basis of the disease including the genetics, biochemistry and pathophysiology of SCD and $\mathrm{PNH}$; there is also the body of experience regarding their clinical features, acquired over decades (or centuries) of basic and clinical research. The area shaded in light pink comprises innovative therapeutic measures produced by PHARMA, based on what was known in the green area, with the incentives and advantages afforded by Orphan Drug Designation (ODD). We are unable to provide, for either SCD or PNH, a $\$$ figure for what is in green, and for what is in pink; however, we contend that a 5:1 ratio may not be an over-estimate. Hydroxyurea (HU) is an important case in point: this compound has been a drug for three-quarters of a century, and has been used in SCD over the last quarter. However, a new formulation, Siklos (containing in one capsule either $1,000 \mathrm{mg}$ or $100 \mathrm{mg}$ instead of $500 \mathrm{mg}$ ) has received designation as an orphan drug: the price per Gram is $\$ 16.50$ instead of about $\$ 1$. In practice, Siklos (not shown in the figure) has managed to move $\mathrm{HU}$ from the green area to the pink area.

and EMA: in essence, a set of financial and regulatory incentives for drugs invented or re-purposed for the treatment of rare diseases.

The definition of rare disease is based on epidemiology: i.e., less than 200,000 patients overall in the US; less than five in 10,000 in EU. These are clearly arbitrary cut-offs, and they are population-sensitive. A paradigmatic example is sickle cell disease (SCD): it qualifies as rare disease in the North of the world, but it is not at all rare in parts of India and particularly in tropical Africa, where the incidence of sickle cell disease (SCD: including the types SS, SC and S-thalassaemia) is of the order of $1 \%$, and in some countries up to $2 \%$ (Piel et al., 2010). A second example is paroxysmal nocturnal haemoglobinuria $(\mathrm{PNH})$ : a disease that is ultra-rare throughout the entire world (Luzzatto et al., 2011a); recently there have been impressive developments in the management of PNH.
The purpose of this paper is to outline, for these two rare diseases, the gaps between optimal current management and current reality in Africa; and to make practical proposals aiming to ameliorate the situation.

With respect to optimal management we have referred to a vast literature, with due attention to recent authoritative reviews for SCD (e.g. (Piel et al., 2017; Ware et al., 2017)) and PNH (e.g. (Hill et al., 2017; Patriquin et al., 2019)). We then analysed what actually happens in Africa: again based on the literature, drawing also from our personal experience. In Tanzania the burden of SCD is high, and a programme aiming to combine clinical care, research, training and advocacy has been running for over 15 years (Makani et al., 2018) and it has become within the continent a hub of wider cooperation named SickleinAfrica (Makani et al., 2020). 


\section{Sickle Cell Disease}

SCD claims more than one "first" in medicine. The very term molecular disease was coined when it was discovered that the basis of SCD was a structural abnormality in the haemoglobin molecule in red cells (Pauling et al., 1949) (Ingram, 1956); then one allele of a DNA restriction fragment length polymorphism was the first found to be genetically linked to the haemoglobin $S$ $H B B^{E 6 V}$ mutation (Kan and Dozy, 1978): this eased the diagnosis of SCD at the DNA level, facilitating prenatal diagnosis (Kazazian et al., 1972); at the same time, it opened up the vast research field currently known as genome wide association studies (GWAS). Prevention based on prenatal diagnosis has been widely successful for thalassemia in Sardinia (Cao and Kan, 2013) and in Cyprus (Bozkurt, 2007); but only in Cuba (another island) for SCD (Marcheco-Teruel, 2019). This important topic falls outside the scope of this paper.

With respect to management of SCD, for decades it has consisted only in the treatment of symptoms, of exacerbations, and of complications (Figure 1). Since the eighties bone marrow transplantation (BMT) was introduced as a curative approach (Vermylen et al., 1994); and a recent review has reported it can cure the disease in $90 \%$ of cases (Iqbal et al., 2021). However, for a variety of reasons only a small minority of patients receive BMT (Bolaños-Meade and Brodsky, 2014): including in the US, where the average cost of this procedure is in the range of $\$ 200,000-400,000$. A survey of three sites in LMICs yields instead a cost of less than $\$ 15,000$ (Faulkner et al., 2021). Based on this last figure, if a child were diagnosed with SCD at the age of 2 , and if she/he were to take HU regularly (see below), by the age of 50 the expenditure on HU would be roughly the same as if BMT had been carried out at the time of diagnosis.

BMT services are already established in six African countries (Harif et al., 2020), but in only one, Nigeria (Bazuaye et al., 2014), of those with a high prevalence of SCD ${ }^{1}$. To date, 17 patients with SCD have received BMT, and 14 have been cured without serious complications $^{2}$. Thus, curative treatment of SCD is achievable in Africa, and it is an example for other centres to follow. An outstanding issue is that patient selection ought to be based on clinical criteria rather than on the ability of an individual patient to pay.

Gene therapy for SCD (see Figure 1) (Ribeil et al., 2017; Abraham and Tisdale, 2021) is a hi-tech procedure whereby the patient's haematopoietic stem cells are 'mobilized', then purified, transduced in vitro with an appropriate vector, checked for successful vector integration, and finally re-infused into the patient. From the clinical point of view this is in essence a modified auto-grafting procedure that requires myelosuppression, but does not require a donor, does not require matching, and does not entail dire immune complications

\footnotetext{
${ }^{1}$ At a conservative estimate the number of patients with SCD in Nigeria is 2.5 million: BMT has been received by probably less than 100 .

${ }^{2}$ This has been possible thanks to the indefatigable efforts of Nosa Bazuaye and his team at the University of Benin Teaching Hospital. For logistic reasons the procedures are currently carried out at the private Celltek Healthcare Medical Center, at a cost to each patient of $\$ 20,000$, i.e. much less than if the patient had travelled in order to have BMT abroad.
}

such as chronic graft versus host disease: therefore it may eventually surpass BMT. Gene therapy for SCD is marketed in the form of Zynteglo, at the price of $\$ 1.8$ million per patient.

With respect to (non-curative) disease-modifying drugs, progress has been slow, until in 1995 the beneficial value of hydroxyurea $^{3}$ (HU) was established (Charache et al., 1995). Over the past quarter-century HU has been used extensively in many countries: including e.g. Cuba, Central America (Svarch et al., 2006) and Brazil (Vicari et al., 2005), in children and in adults. There was no reason for not using it in Africa (Luzzatto et al., 2011b); but only recently highly significant beneficial effects have been formally demonstrated in a multi-centre trial involving Congo, Kenya, Uganda and Angola (Tshilolo et al., 2019). HU is effective as long as it is taken: that means, in most cases, for a lifetime. Since there are no published data on unselected patient populations, we have polled seven colleagues who have ample experience in three countries with high prevalence of SCD (Nigeria, DRC, Ghana). From the responses received and from our experience we estimate that SCD patients in Africa taking HU regularly are less than $20 \%$.

The obvious question is: why? In a well-rehearsed analysis of potential 'barriers', the following have been listed (Adeyemo et al., 2019): lack of national guidelines, concerns about infertility, carcinogenic potential and side effects, high cost and unavailability of $\mathrm{HU}$, difficulty in compounding paediatric dosages, need for toxicity surveillance, lack of time/skill to explain risks/benefits, insufficient experience or knowledge regarding mechanism of action, doubts about effectiveness, safety profile of $\mathrm{HU}$ in pregnancy and lactation, patients' unwillingness. Clearly this is a mix of reservations of varying weight, some from patients and some from health workers: but buried in the midst is the stark item of cost. Quoting from another paper (Ryan et al., 2020): "Physicians only prescribed hydroxyurea therapy when they perceive the patient can afford the medicine; and patients reported they only use hydroxyurea therapy when they have funds to pay out-of-pocket". In Africa the cost of $1 \mathrm{G}$ of $\mathrm{HU}$ (the average daily dose for an adult with SCD) generally ranges from $\$ 0.5$ to $\$ 1.0$ (Costa et al., 2021). The problem of course is that, unlike with an acute disease, with SCD this cost must be born for a lifetime. The data above strongly suggest that in the vast majority of cases the main barrier that limits access to regular $\mathrm{HU}$ is financial. Indeed, when this medicine was produced locally by galenic compounding and offered to patients free of charge (Costa et al., 2021), the

\footnotetext{
${ }^{3} \mathrm{HU}$ is an inhibitor of ribonucleoside diphosphate reductase, and therefore of DNA synthesis. It has been used in the management of many malignant disorders, and today it is still standard of care in many patients with myeloproliferative neoplasms. One characteristic advantage of $\mathrm{HU}$, compared to other chemotherapeutic agents, is that its toxicity is reversible. HU ameliorates SCD through at least two different mechanisms (see Figure 1). On one hand, by inhibiting cell division in the later stages of erythropoiesis, it favours the synthesis of foetal haemoglobin ( $\mathrm{Hb} \mathrm{F}$ ): insertion of a $\mathrm{Hb} F$ molecule hinders polymerization of deoxy-Hb S, thus decreasing sickling (Faulkner et al., 2021). On the other hand, it decreases the neutrophil count, thus reducing the detrimental effects of the chronic inflammatory state that tends to be permanent in SCD patients (Harif et al., 2020).
} 
uptake was $100 \%$. In Nigeria a local industry has been sensitive to the demand arising from a 'rare disease' that is not rare in that country, and has knocked down the price to $\$ 0.13$ (see (Galadanci et al., 2019)): we can hope that others will follow this example.

\section{Paroxysmal Nocturnal Haemoglobinuria}

$\mathrm{PNH}$, like SCD, is a chronic haemolytic anemia; however, unlike SCD, it is acquired rather than inherited and, unlike SCD, it is an ultra-rare disease in every country of the world. For decades the only curative treatment has been BMT (Saso et al., 1999); the alternative was supportive treatment, including blood transfusion whenever necessary. $\mathrm{PNH}$ is a prototype of a non-malignant clonal disorder (Oni et al., 1970) that develops on a background of aplastic anaemia (Luzzatto and Risitano, 2018), through the expansion of a clone originating from a haematopoietic stem cell that has a somatic mutation in the PIGA gene (Takeda et al., 1993), that encodes an enzyme protein required for the biosynthesis of glycosyl-phosphatidylinositol (GPI). Since CD55 and CD59, two regulators of complement, are GPI-linked, they are deficient on the surface of $\mathrm{PNH}$ red cells: indeed hemolysis in $\mathrm{PNH}$ is complement-dependent. Peter Hillmen, in collaboration with Russell P Rother at Alexion, first explored complement blockade in PNH patients (Hillmen et al., 2004). Thereafter, a phase III trial of the anti-C5 monoclonal antibody eculizumab (ECU) (Hillmen et al., 2006) led to its approval by FDA and EMA as the first "PNH drug",

The term revolutionary is sometimes over-used nowadays, but in this case it is a fact that the life of many $\mathrm{PNH}$ patients has been gratifyingly changed in quality, and also in duration (Kelly et al., 2011). In PNH C5 blockade, by preventing formation of the Membrane Attack Complex in the distal complement pathway (see Figure 1), abrogates intravascular haemolysis, the most disturbing pathophysiologic feature, that may contribute to life-threatening thrombosis. ECU also exemplifies how a major therapeutic innovation can be achieved: understanding the complement cascade, elucidating the pathogenesis of $\mathrm{PNH}$, inventing monoclonal antibodies has required several decades of research in academic institutions; then, within a few years, a small company powered by state of the art technology was able to produce ECU. Although this successful combination did not arise through a deliberate public-private partnership, this is what it was. We can only applaud, until we look at the price: ECU is sold at about $\$ 400,000$ per patient per year. There are today in the world a few thousands patients who have received ECU for at least 10 years: each one of them has cost to a National Health Service in the EU, or to an insurer in the US, at least \$4 million; despite the fact that ECU has had the perks of an orphan drug, and the company producing it has not paid any royalties to those who discovered $\mathrm{PNH}$, complement, monoclonal antibodies. It just feels like there is something wrong here.

ECU has been a trailblazer. Soon after it was introduced, it became clear that preventing the haemolysis of $\mathrm{PNH}$ red cells had a down side: the un-lysed red cells are now opsonized by the complement component $\mathrm{C} 3 \mathrm{~d}$, and thus become prey to macrophages (Risitano et al., 2009). This iatrogenic extravascular hemolysis is less severe and has less pathological consequences than the intravascular hemolysis of untreated $\mathrm{PNH}$ patients; but it has been a stimulus to try and do better. Three new molecules that target the proximal complement pathway, upstream of $\mathrm{C} 5$, are now on track to become medicines for $\mathrm{PNH}$, and more are in the pipeline. ECU has been a trailblazer, unfortunately, also with respect to price: in this respect new molecules are likely to converge on using ECU as a benchmark. Indeed, pegcetacoplan (Hillmen et al., 2021), that is already FDA-approved, has a price-tag of $\$ 458,000$ per year.

Since PNH is ultra-rare, it is not surprising that there have been very few cases reported from Africa (Manuel, 1969; Oni et al., 1970; Rizk et al., 2002; Lumori and Muyanja, 2019); in Tanzania we have so far diagnosed four patients (Ally et al., 2019). At the moment, as far as we know, ECU is not available in Africa, or in most Asian countries (including India and China), or in most countries in Latin America, and even in some EU countries. One of us, on account of age, has some experience of managing $\mathrm{PNH}$ from the pre-ECU era: but in one severe case we have formally requested from the Alexion company this drug on a compassionate basis, since it is not licensed in Tanzania: the request was declined.

\section{DISCUSSION}

The provision of medicines operates in today's world within a framework that has a built-in source of conflict. Drugs produced by the pharmaceutical industry (PHARMA), owned and run by private enterprise, are then purchased and used by the health services that, in Europe (EU and $\mathrm{UK})$, are public; in the US the health system is largely private (it is often referred to as the health industry), but with a substantial public component (the Veterans Administration, Medicare and Medicaid); while a variety of systems are operating in the rest of the world. Thus, National Health Services funded by taxpayers' money must contend with PHARMA, that is legally entitled to earn maximum profit ${ }^{4}$. In the US the PHARMA industry and a large part of the health industry, that are both for profit, are frequently pitched against each other on account of drug prices.

This conflict poses serious problems. Eliminating profit from PHARMA did not work in the former Soviet Union, where the industry failed; but currently PHARMA maximizes profits by leveraging the fact that health services have an institutional obligation to provide the best care to all: this situation is fraught with risk, because the health services may collapse. We think that, as in many societal issues, human intelligence ought to find a balance: although, at the moment, there seems to be no mechanism in place to do so. FDA in the US and EMA in EU are doing generally a good job in assessing safety and

${ }^{4}$ In informal discussions we have heard PHARMA executives saying that if they relent on extracting the highest possible drug prices from "customers", they might be sued for damages by shareholders. 
effectiveness, but they are excluded from price negotiations. Although it is claimed that prices take into account value for money, assessment of value is based on dubious and ethically questionable quality-adjusted life-years (QALY); and there has been no agreement on the $\$$ figure for $1 \mathrm{QALY}^{5}$. The stark reality is that, at the moment, the price of drugs is dictated entirely by willingness to pay.

We think at least three points deserve consideration. First, whereas drugs are patented as inventions, they could not have been invented without an enormous body of knowledge that preexisted $^{6}$ : see the pink area versus the green area in Figure 1. Second, the Orphan Drugs Act has been a success because patients receive new drugs, and PHARMA have discovered that investment in rare diseases-formerly a non-starter-can become a coveted area for venture capitalists: however, an Act that has offered incentives and benefits for developing a new drug, is silent about the basis on which that drug will be eventually priced (Luzzatto et al., 2018). Third, a recurrent objection to controlling prices is that this will limit profits accruing to investors, and high profits are precisely what is fuelling innovative drug development. However, all of the five top PHARMA companies spend less for $\mathrm{R} \& \mathrm{D}$ than they do for marketing (up to $42 \%$ of revenue: see https://www. pharmacychecker.com/askpc/pharma-marketing-researchdevelopment $/)^{7}$.

We are not qualified to resolve, even in theory, this megaconflict. As regards Africa, we cannot ignore the historical debt on the shoulders of ex-colonial powers that have exploited this continent for one century or longer. This debt has never been recognized on the legal level, and rarely on the political level. However, in the area of health there have been "aid" programmes: for instance, since 2002 the Global Fund has disbursed, in the fight against HIV, tuberculosis and malaria, more than $\$ 45$ billion, $74 \%$ of which went to sub- Saharan Africa (https://www. theglobalfund.org/en/overview/). On a much smaller scale, an example worthy of note is that of imatinib: this drug is made available to patients with chronic myeloid leukaemia (CML) in Tanzania and in other countries through the glivec International's Patient Assistance Program, established by

\footnotetext{
${ }^{5}$ The Incremental Cost-Effectiveness Ratio (ICER), an elaboration on QALY adopted by the National Institute for Health and Care Excellence (NICE), may be appropriate when one course of a drug can produce definitive cure (e.g. sofosbuvir for hepatitis C), or may prolong survival substantially (e.g. bevacizumab in cases of colon cancer); it breaks down for drugs that must be used for an indefinite period of time. Based on ICER, eculizumab at $\$ 400,000$ per year should never have been approved for funding by the NHS.

${ }^{6}$ The so-called R\&D costs incurred to bring a drug to the market are in large part those of clinical trials. The average cost of a phase 3 trial has been estimated to be $\$ 19$ million (Moore et al., 2018). Thus, it is a small component of the total cost of getting a drug approved by FDA, estimated to be 1-2 billion, and that includes, for instance, the compensation of the CEO of the company, that may be several million per year.

${ }^{7}$ It is hard to understand why, in the case of rare diseases, any marketing is required at all. Expensive drugs for rare disease should be prescribed and managed by highly specialized professionals who are thoroughly familiar with new drugs within their specialty: either they have learnt current guidelines and recommendations, or they have written them.
}

Novartis and implemented in partnership with the Max Foundation (see (Nasser et al., 2021)). A limitation of these approaches is that the choices are made by the "donors", not by the receivers: as a result we have to say-even though it sounds crude-that for a person in Tanzania it is financially preferable to have HIV disease or CML rather than SCD.

We think that one needs short-term devices and long-term solutions. In the short term, we call for SCD to be added to the agenda of the Global Fund. They have focused hitherto on three communicable diseases, based on the notion that they can be potentially eliminated more easily than an inherited disease: however, the reality in Africa is that we are very far from the elimination end-point, but at least the burden imposed on the population by these three diseases is being alleviated: exactly the same would be true for SCD if HU and other drugs were provided; and a good way to do this would be to give grants to local industry to produce them. At the same time, we call for a voluntary move by PHARMA, whereby for every patient with a rare disease who receives an expensive drug covered by NHS or by private insurance, the same drug should be provided at a symbolic price to one patient in a LMIC, particularly in Africa.

In the long term, we have no doubt that in Africa, like everywhere else, it is for each country's government to look after the health of their people as a high priority-whether through a national health service or otherwise. In this respect, they will find ways to increase local production of medicines. With respect to expensive drugs for rare diseases, African countries, like the others, will have to decide how to negotiate prices with PHARMA: perhaps they will choose to do it through the African Union organization, that will be thus enabled to negotiate on behalf of 1.3 billion people.

\section{DATA AVAILABILITY STATEMENT}

The original contributions presented in the study are included in the article/Supplementary Material, further inquiries can be directed to the corresponding author.

\section{AUTHOR CONTRIBUTIONS}

All authors listed have made a substantial, direct, and intellectual contribution to the work and approved it for publication.

\section{ACKNOWLEDGMENTS}

We are very grateful to all colleagues with whom we have shared work in basic and clinical research, both in SPARCO and elsewhere; and particularly to patients with SCD and PNH in different parts of the world, from whom we have learnt. We thank Enrico Costa for prior discussions and for help in preparing the figure. 


\section{REFERENCES}

Abraham, A. A., and Tisdale, J. F. (2021). Gene Therapy for Sickle Cell Disease: Moving from the Bench to the Bedside. Blood 138, 932-941. doi:10.1182/ blood.2019003776

Adeyemo, T. A., Diaku-Akinwunmi, I. N., Ojewunmi, O. O., Bolarinwa, A. B., and Adekile, A. D. (2019). Barriers to the Use of Hydroxyurea in the Management of Sickle Cell Disease in Nigeria. Hemoglobin 43, 188-192. doi:10.1080/ 03630269.2019.1649278

Ally, M., Magesa, P., and Luzzatto, L. (2019). High Frequency of Acquired Aplastic Anemia in Tanzania. Am. J. Hematol. 94, E86-E88. doi:10.1002/ajh.25388

Bazuaye, N., Nwogoh, B., Ikponmwen, D., Irowa, O., Okugbo, S., Isa, I., et al. (2014). First Successful Allogeneic Hematopoietic Stem Cell Transplantation for a Sickle Cell Disease Patient in a Low Resource Country (Nigeria): a Case Report. Ann. Transpl. 19, 210-213. doi:10.12659/AOT.890248

Bolaños-Meade, J., and Brodsky, R. A. (2014). Blood and Marrow Transplantation for Sickle Cell Disease: Is Less More? Blood Rev. 28, 243-248. doi:10.1016/ j.blre.2014.08.001

Bozkurt, G. (2007). Results from the north cyprus Thalassemia Prevention Program. Hemoglobin 31, 257-264. doi:10.1080/03630260701297204

Cao, A., and Kan, Y. W. (2013). The Prevention of Thalassemia. Cold Spring Harb Perspect. Med. 3, a011775. doi:10.1101/cshperspect.a011775

Charache, S., Terrin, M. L., Moore, R. D., Dover, G. J., Barton, F. B., Eckert, S. V., et al. (1995). Effect of Hydroxyurea on the Frequency of Painful Crises in Sickle Cell Anemia. Investigators of the Multicenter Study of Hydroxyurea in Sickle Cell Anemia. N. Engl. J. Med. 332, 1317-1322. doi:10.1056/ NEJM199505183322001

Costa, E., Tibalinda, P., Sterzi, E., Leufkens, H. M. G., Makani, J., Kaale, E., et al. (2021). Making Hydroxyurea Affordable for Sickle Cell Disease in Tanzania Is Essential (HASTE): How to Meet Major Health Needs at a Reasonable Cost. Am. J. Hematol. 96, E2-E5. doi:10.1002/ajh.26007

Faulkner, L., Verna, M., Rovelli, A., Agarwal, R. K., Dhanya, R., Parmar, L., et al.Pediatric Diseases Working Party of the European Blood and Marrow Transplantation Group (2021). Setting up and Sustaining Blood and Marrow Transplant Services for Children in Middle-Income Economies: an ExperienceDriven Position Paper on Behalf of the EBMT PDWP. Bone Marrow Transpl. 56, 536-543. doi:10.1038/s41409-020-0983-5

Galadanci, A. A., Galadanci, N. A., Jibir, B. W., Abdullahi, S. U., Idris, N., Gambo, S., et al. (2019). Approximately 40000 Children with Sickle Cell Anemia Require Screening with TCD and Treating with Hydroxyurea for Stroke Prevention in Three States in Northern Nigeria. Am. J. Hematol. 94, E305-E307. doi:10.1002/ajh.25616

Harif, M., Weisdorf, D., Novitzky, N., Szer, J., Mahmal, L., Benakli, M., et al. (2020). Special Report: Summary of the First Meeting of African Blood and Marrow Transplantation (AfBMT) Group, Casablanca, Morocco, April 19-21, 2018 Held under the Auspices of the Worldwide Network for Blood and Marrow Transplantation (WBMT). Hematol. Oncol. Stem Cel Ther 13, 202-207. doi:10.1016/j.hemonc.2019.05.003

Hill, A., DeZern, A. E., Kinoshita, T., and Brodsky, R. A. (2017). Paroxysmal Nocturnal Haemoglobinuria. Nat. Rev. Dis. Primers 3, 17028. doi:10.1038/ nrdp.2017.28

Hillmen, P., Hall, C., Marsh, J. C., Elebute, M., Bombara, M. P., Petro, B. E., et al. (2004). Effect of Eculizumab on Hemolysis and Transfusion Requirements in Patients with Paroxysmal Nocturnal Hemoglobinuria. N. Engl. J. Med. 350, 552-559. doi:10.1056/NEJMoa031688

Hillmen, P., Szer, J., Weitz, I., Röth, A., Höchsmann, B., Panse, J., et al. (2021). Pegcetacoplan versus Eculizumab in Paroxysmal Nocturnal Hemoglobinuria. N. Engl. J. Med. 384, 1028-1037. doi:10.1056/NEJMoa2029073

Hillmen, P., Young, N. S., Schubert, J., Brodsky, R. A., Socié, G., Muus, P., et al. (2006). The Complement Inhibitor Eculizumab in Paroxysmal Nocturnal Hemoglobinuria. N. Engl. J. Med. 355, 1233-1243. doi:10.1056/ NEJMoa061648

Ingram, V. M. (1956). A Specific Chemical Difference between the Globins of normal Human and Sickle-Cell Anaemia Haemoglobin. Nature 178, 792-794. doi:10.1038/178792a0

Iqbal, M., Reljic, T., Corbacioglu, S., de la Fuente, J., Gluckman, E., Kumar, A., et al. (2021). Systematic Review/Meta-Analysis on Efficacy of Allogeneic
Hematopoietic Cell Transplantation in Sickle Cell Disease: An International Effort on Behalf of the Pediatric Diseases Working Party of European Society for Blood and Marrow Transplantation and the Sickle Cell Transplantation International Consortium. Transpl. Cel Ther 27, 167-e12. doi:10.1016/ j.jtct.2020.10.007

Kan, Y. W., and Dozy, A. M. (1978). Polymorphism of DNA Sequence Adjacent to Human Beta-Globin Structural Gene: Relationship to Sickle Mutation. Proc. Natl. Acad. Sci. U S A. 75, 5631-5635. doi:10.1073/pnas.75.11.5631

Kazazian, H. H., Jr., Kaback, M. M., Woodhead, A. P., Leonard, C. O., and Nersesian, W. S. (1972). Further Studies on the Antenatal Detection of Sickle Cell Anemia and Other Hemoglobinopathies. Adv. Exp. Med. Biol. 28, 337-346. doi:10.1007/978-1-4684-3222-0_27

Kelly, R. J., Hill, A., Arnold, L. M., Brooksbank, G. L., Richards, S. J., Cullen, M., et al. (2011). Long-term Treatment with Eculizumab in Paroxysmal Nocturnal Hemoglobinuria: Sustained Efficacy and Improved Survival. Blood 117, 6786-6792. doi:10.1182/blood-2011-02-333997

Lumori, B. A. E., and Muyanja, D. (2019). Diagnostic and Treatment Challenges of Paroxysmal Nocturnal Hemoglobinuria in Uganda. Case Rep. Hematol. 2019, 7897509. doi:10.1155/2019/7897509

Luzzatto, L. (2021). Control of Hemolysis in Patients with PNH. Blood 138, 1908-1910. doi:10.1182/blood.2021013169

Luzzatto, L., Fasola, F., and Tshilolo, L. (2011). Haematology in Africa. Br. J. Haematol. 154, 777-782. doi:10.1111/j.1365-2141.2011.08763.x

Luzzatto, L., Gianfaldoni, G., and Notaro, R. (2011). Management of Paroxysmal Nocturnal Haemoglobinuria: a Personal View. Br. J. Haematol. 153, 709-720. doi:10.1111/j.1365-2141.2011.08690.x

Luzzatto, L., Hyry, H. I., Schieppati, A., Costa, E., Simoens, S., Schaefer, F., et al.Second Workshop on Orphan Drugs participants (2018). Outrageous Prices of Orphan Drugs: a Call for Collaboration. Lancet 392, 791-794. doi:10.1016/S0140-6736(18)31069-9

Luzzatto, L., and Risitano, A. M. (2018). Advances in Understanding the Pathogenesis of Acquired Aplastic Anaemia. Br. J. Haematol. 182, 758-776. doi:10.1111/bjh.15443

Makani, J., Tluway, F., Makubi, A., Soka, D., Nkya, S., Sangeda, R., et al. (2018). A Ten Year Review of the Sickle Cell Program in Muhimbili National Hospital, Tanzania. BMC Hematol. 18, 33. doi:10.1186/s12878-018-0125-0

Makani, J., Sangeda, R. Z., Nnodu, O., Nembaware, V., Osei-Akoto, A., Paintsil, V., et al. (2020). SickleInAfrica. Lancet Haematol. 7, e98-e99. doi:10.1016/s23523026(20)30006-5

Manuel, M. A. (1969). Paroxysmal Nocturnal Haemoglobinuria in Two South African Bantu Patients. S Afr. Med. J. 43, 351-354.

Marcheco-Teruel, B. (2019). Sickle Cell Anemia in Cuba: Prevention and Management, 1982-2018. MEDICC Rev. 21, 34-38.

Moore, T. J., Zhang, H., Anderson, G., and Alexander, G. C. (2018). Estimated Costs of Pivotal Trials for Novel Therapeutic Agents Approved by the US Food and Drug Administration, 2015-2016. JAMA Intern. Med. 178, 1451-1457. doi:10.1001/jamainternmed.2018.3931

Nasser, A., Hussein, A., Chamba, C., Yonazi, M., Mushi, R., Schuh, A., et al. (2021). Molecular Response to Imatinib in Patients with Chronic Myeloid Leukemia in Tanzania. Blood Adv. 5, 1403-1411. doi:10.1182/bloodadvances.2020002973

Oni, S. B., Osunkoya, B. O., and Luzzatto, L. (1970). Paroxysmal Nocturnal Hemoglobinuria: Evidence for Monoclonal Origin of Abnormal Red Cells. Blood 36, 145-152. doi:10.1182/blood.v36.2.145.145

Patriquin, C. J., Kiss, T., Caplan, S., Chin-Yee, I., Grewal, K., Grossman, J., et al. (2019). How We Treat Paroxysmal Nocturnal Hemoglobinuria: A Consensus Statement of the Canadian PNH Network and Review of the National Registry. Eur. J. Haematol. 102, 36-52. doi:10.1111/ejh.13176

Pauling, L., Itano, H. A., Singer, S. J., and Wells, I. C. (1949). Sickle Cell Anemia a Molecular Disease. Science 110, 543-548. doi:10.1126/science.110.2865.543

Piel, F. B., Patil, A. P., Howes, R. E., Nyangiri, O. A., Gething, P. W., Williams, T. N., et al. (2010). Global Distribution of the Sickle Cell Gene and Geographical Confirmation of the Malaria Hypothesis. Nat. Commun. 1, 104. doi:10.1038/ ncomms1104

Piel, F. B., Steinberg, M. H., and Rees, D. C. (2017). Sickle Cell Disease. N. Engl. J. Med. 376, 1561-1573. doi:10.1056/NEJMra1510865

Ribeil, J. A., Hacein-Bey-Abina, S., Payen, E., Magnani, A., Semeraro, M., Magrin, E., et al. (2017). Gene Therapy in a Patient with Sickle Cell Disease. N. Engl. J. Med. 376, 848-855. doi:10.1056/NEJMoa1609677 
Risitano, A. M., Notaro, R., Marando, L., Serio, B., Ranaldi, D., Seneca, E., et al. (2009). Complement Fraction 3 Binding on Erythrocytes as Additional Mechanism of Disease in Paroxysmal Nocturnal Hemoglobinuria Patients Treated by Eculizumab. Blood 113, 4094-4100. doi:10.1182/blood-2008-11189944

Rizk, S., Ibrahim, I. Y., Mansour, I. M., and Kandil, D. (2002). Screening for Paroxysmal Nocturnal Hemoglobinuria (PNH) Clone in Egyptian Children with Aplastic Anemia. J. Trop. Pediatr. 48, 132-137. doi:10.1093/tropej/ 48.3.132

Ryan, N., Dike, L., Ojo, T., Vieira, D., Nnodu, O., Gyamfi, J., et al. (2020). Implementation of the Therapeutic Use of Hydroxyurea for Sickle Cell Disease Management in Resource-Constrained Settings: a Systematic Review of Adoption, Cost and Acceptability. BMJ Open 10, e038685. doi:10.1136/ bmjopen-2020-038685

Saso, R., Marsh, J., Cevreska, L., Szer, J., Gale, R. P., Rowlings, P. A., et al. (1999). Bone Marrow Transplants for Paroxysmal Nocturnal Haemoglobinuria. Br. J. Haematol. 104, 392-396. doi:10.1046/j.13652141.1999.01195.x

Svarch, E., Machín, S., Nieves, R. M., Mancia de Reyes, A. G., Navarrete, M., and Rodríguez, H. (2006). Hydroxyurea Treatment in Children with Sickle Cell Anemia in Central America and the Caribbean Countries. Pediatr. Blood Cancer 47, 111-112. doi:10.1002/pbc.20823

Takeda, J., Miyata, T., Kawagoe, K., Iida, Y., Endo, Y., Fujita, T., et al. (1993). Deficiency of the GPI Anchor Caused by a Somatic Mutation of the PIG-A Gene in Paroxysmal Nocturnal Hemoglobinuria. Cell 73, 703-711. doi:10.1016/ 0092-8674(93)90250-t

Tshilolo, L., Tomlinson, G., Williams, T. N., Santos, B., Olupot-Olupot, P., Lane, A., et al. (2019). Hydroxyurea for Children with Sickle Cell Anemia in
Sub-saharan Africa. N. Engl. J. Med. 380, 121-131. doi:10.1056/ NEJMoa 1813598

Vermylen, C., Cornu, G., Ferster, A., Sariban, E., Pinkel, D., and Garfunkel, J. M. (1994). Bone Marrow Transplantation for Sickle Cell Anemia. J. Pediatr. 124, 329-330. doi:10.1016/s0022-3476(94)70331-0

Vicari, P., Barretto de Mello, A., and Figueiredo, M. S. (2005). Effects of Hydroxyurea in a Population of Brazilian Patients with Sickle Cell Anemia. Am. J. Hematol. 78, 243-244. doi:10.1002/ajh.20293

Ware, R. E., de Montalembert, M., Tshilolo, L., and Abboud, M. R. (2017). Sickle Cell Disease. Lancet 390, 311-323. doi:10.1016/S0140-6736(17) 30193-9

Conflict of Interest: The authors declare that the research was conducted in the absence of any commercial or financial relationships that could be construed as a potential conflict of interest.

Publisher's Note: All claims expressed in this article are solely those of the authors and do not necessarily represent those of their affiliated organizations, or those of the publisher, the editors and the reviewers. Any product that may be evaluated in this article, or claim that may be made by its manufacturer, is not guaranteed or endorsed by the publisher.

Copyright (C) 2022 Luzzatto and Makani. This is an open-access article distributed under the terms of the Creative Commons Attribution License (CC BY). The use, distribution or reproduction in other forums is permitted, provided the original author(s) and the copyright owner(s) are credited and that the original publication in this journal is cited, in accordance with accepted academic practice. No use, distribution or reproduction is permitted which does not comply with these terms. 